\title{
REVIEW
}

\section{Stem cell banking: between traceability and identifiability}

\author{
Bartha M Knoppers* and Rosario Isasi
}

\begin{abstract}
Stem cell banks are increasingly seen as an essential resource of biological materials for both basic and translational research. Stem cell banks support transnational access to quality-controlled and ethically sourced stem cell lines from different origins and of varying grades. According to the Organisation for Economic Co-operation and Development, advances in regenerative medicine are leading to the development of a bioeconomy, 'a world where biotechnology contributes to a significant share of economic output'. Consequently, stem cell banks are destined to constitute a pillar of the bioeconomy in many countries. While certain ethical and legal concerns are specific to the nature of stem cells, stem cell banking could do well to examine the approaches fostered by tissue banking generally. Indeed, the past decade has seen a move to simplify and harmonize biological tissue and data banking so as to foster international interoperability. In particular, the issues of consent and of traceability illustrate not only commonalities but the opportunity for stem cell banking to appreciate the lessons learned in biobanking generally. This paper analyzes convergence and divergence in issues surrounding policy harmonization, transnational sharing, informed consent, traceability and return of results in the context of stem cell banks.
\end{abstract}

\section{Introduction}

Since the pioneering isolation and culture of human embryonic stem cells over a decade ago, a new era of clinical promise in regenerative medicine has emerged. Stem cell research will improve our ability to prevent and cure disease by providing cells for organ transplantation and cell therapies. It will also be used to create a

*Correspondence: Bartha.Knoppers@mcgill.ca

Centre of Genomics and Policy, McGill University, 740 Dr Penfield Avenue, Suite 5206, Montreal, QC, H3A 1A4, Canada successful model system for drug discovery, including the development of new testing methods for drug efficacy, toxicity and safety, and provide a deeper understanding of the processes of human cell differentiation and development for the treatment of diseases such as cancer [1].

Given the scientific potential of the field, stem cell banks are increasingly seen as an essential resource of biological materials for both basic and translational research. Stem cell banks and registries support transnational access to quality-controlled and ethically sourced stem cell lines from different origins and of varying grades - for example, research versus clinical. They are also the 'de facto' depositories of 'biological standards' [2]. According to the Organisation for Economic Cooperation and Development, advances in regenerative medicine and stem cells are leading to the development of a bioeconomy: 'a world where biotechnology contributes to a significant share of economic output' [3]. Consequently, stem cell banks are destined to constitute a pillar of the bioeconomy of many countries.

International initiatives are emerging to address harmonization and standardization processes for stem cell research and banking; these include the International Society for Stem Cell Research (ISSCR) and the International Stem Cell Banking Initiative (ISCBI). Until recently, these efforts adopted an 'embryo-centric' approach, leaving behind other timely and promising sources, such as induced pluripotent stem (iPs) cells or those derived from placentas and umbilical cords, among others. Today, the size and the scope of the collections are growing, as witnessed by the increasing number of registries of disease biological samples and iPs cell lines [4-6].

Stem cell banks are poised to maintain internal consistency with respect to policy frameworks relating to the permissibility of conducting stem cell research [7]. However, due to the heterogeneous nature of these policy approaches and their lack of interoperability, uncertainties remain on the legality of certain practices, such as, for instance, material derivation and distribution [8]. Similarly, uncertainties exist with respect to the ethics of both national and cross-border material and data use. Currently, the self-regulatory approaches applied to the 
political and ethical issues raised here, as we shall see, are characteristic of the biobanking world in general [9].

The term 'stem cell bank' itself can refer to a number of different levels and types of operations, as well as institutions [10]. It can refer to a centralized institute that provides cell stocks for research (for example, the Singapore Stem Cell Bank), a national supply centre, or a repository of human embryonic stem cells (hESCs) for a broad range of researchers (for example, the Indian National Centre for Stem Cell Science). Similarly, stem cell banks range from public banks, as for instance the UK Stem Cell Bank and the Spanish National Stem Cell Bank, to institutional banks, such as the Stem Cell Research Centre, Kyoto University, Japan, and commercial banks (for example, the WISC Bank of WiCell, Madison, WI, USA). Finally, the term 'stem cell bank' can also refer to registries or databases cataloguing or documenting the scientific and ethical provenance of the stem cell lines; examples of registries include the European Human Embryonic Stem Cell Registry and the UMass International Stem Cell Registry. Here, we use the term 'stem cell bank' to encompass the wide range of institutions referred to above.

Biobanking has been defined as 'structured resources that can be used for the purpose of genetic research and which include: (a) human biological materials and/or information generated from the analysis of the same, and (b) extensive associated information' [11]. Even within biobanking, distinctions remain between those studies that are populational or retrospective, and those that use clinical residual tissues [11]. Population biobanks are usually longitudinal and serve as resources for future unspecified research. Retrospective research is increasingly using collections of residual samples leftover after medical care or from pathology archives. To a lesser extent, anonymized collections (irreversibly delinked) can also be of interest as controls. 'Size matters' [12] in understanding gene-environment interactions and normal genomic variation, and because of this there has been a phenomenal growth in biobanking. Indeed, in 2009, Time magazine [13] recognized 'biobanks' as one of the 'top 10 ideas changing the world'.

Like biobanks, stem cell banks have as a core objective to avoid redundancy in research projects and to eliminate the need for the collection and derivation of additional human materials. They aim to ensure the quality, availability and ethical provenance of tissues, cells or embryos used for research and eventual therapies. It is interesting to note that tissue banks and stem cell banks are encountering issues similar to those found in international biobanking generally; these issues include institutional governance, respect of autonomy and privacy, uses of samples, and so on. Both face similar challenges of ensuring safety through traceability, while protecting the autonomy and privacy of donors.
It is in this tension between traceability and privacy that some of the lessons learned in the human tissue banking field (particularly since the advent of population biobanking) may prove to be instructive for stem cell banking. Some banking issues remain particular to the field of stem cells, such as those posed by the development of innovative sources and uses of stem cell lines, including embryonic, adult and cord blood, and placenta [8]. Nevertheless, issues relating to the legitimacy, independence, transparency and governance of banking activities are present in both. These issues with their concomitant challenges are even more critical in the case of stem cell banks, given the political, social and ethical controversies that have historically surrounded embryonic stem cell research.

Of particular importance are the ethical and policy issues surrounding recent scientific advances pertaining to non-embryonic sources of stem cell lines (that is, iPS cells). The discovery of iPS cells was considered to be a scientific breakthrough that would eliminate the major socioethical and policy concerns that have beset embryonic sources [14]. It has been argued that iPS cells do not pose major ethical or legal concerns, and that they should be regulated under the general rules for tissue donation $[15,16]$. However, these arguments are far from being valid. For example, the 'virtual genetic identity between iPS and donor cells raises particular concerns regarding respect for donors' [17], in terms of protecting their autonomy and consent, as well as privacy and confidentiality; the latter is of particular importance given the potential traceability of stem cell lines [18]. Likewise, the possibility of reprogramming such cells back to their origins [19] re-introduces the 'embryonic' issues. Consequently, appropriate mechanisms and ethical and legal approaches to solve challenges related to informed consent, privacy and confidentiality, commercialization, and the safety of human research participants are yet to be defined for stem cell banking.

While certain ethical and legal concerns are specific to the nature of stem cells (especially hESCs), stem cell banking could do well to examine the approaches fostered by tissue banking generally. Indeed, the past decade has seen a move to simplify and harmonize biological tissue and data banking so as to foster international interoperability [20]. In particular, the issues of consent, traceability and, more recently, return of results illustrate not only commonalities but the opportunity for stem cell banking to appreciate the lessons learned in biobanking generally.

\section{Harmonization and international cooperation}

Human tissue banks and related international initiatives, such as the Organisation for Economic Co-operation and Development $[11,21]$ and the International Society for 
Biological and Environmental Repositories [22], have long addressed issues of safety and harmonization, while stem cell banks, beginning with the fundamental step of registries [23], have only recently joined this effort. Indeed, the expansion of stem cell banking efforts was not initially followed by a discussion about the appropriate mechanisms for domestic and international banking governance, as well as the need for both harmonization and international collaboration.

A recent comprehensive study analyzing harmonization and networking practices and trends in European biobanks [24] identified the lack of concerted efforts, together with heterogeneous policy approaches and practices, as threats to their sustainability. When collaboration and the sharing of samples and data are jeopardized, then the raison dêtre of the biobank is also put in jeopardy. In the context of embryonic stem cell banking, our previous research also identified similar gaps and situations where the lack of concerted effort is impeding transnational and translational research [23]. All of this is in striking contrast with current population studies involving biobanking; these are rapidly becoming interoperable [25] and, despite different legal regimes, international collaborative research is becoming a reality [26].

In the stem cell field, international initiatives are now emerging to address harmonization and standardization processes for research and banking. These initiatives, like their population biobank counterparts, share the vision of scientific research as a global enterprise. For instance, the ISCBI of the International Stem Cell Forum has been established with the goal of creating a set of international minimum standards (or best practice guidelines) for banking, characterization and testing of stem cell lines. The mission of the ISCBI is to create a solid scientific and ethical framework for international stem cell banking and research. Thus, a major objective of the ISCBI is the establishment of a global and interoperable network of stem cell banks [27].

In 2008, the ISCBI adopted its first best practices guidelines: the Consensus Guidance for Banking and Supply of Human Embryonic Stem Cell Lines for Research Purposes [28], which standardizes best practice for the banking, testing and distribution of hESCs for research purposes. The guidance covers a wide range of processes involved in stem cell banking, including procurement of cell lines, cell banking procedures and documentation, cell banking quality control, and the process of releasing cell banks. It also establishes technical requirements, such as release criteria, microbiological testing, cell characterization and shipment of cells, and it addresses core ethical issues, such as informed consent, oversight and licensing, and traceability and documentation of cell provenance. In 2011, the ISCBI is expected to launch similar best practice guidelines directed at clinical grade embryonic stem cell lines.

Other important harmonization and standardization efforts are carried out by the European Human Embryonic Stem Cell Registry, the ISSCR (Registry of Human Embryonic Stem Cell Line Provenance) and the International Stem Cell Registry (ISCR) of hESC lines and iPs cell lines launched by the University of Massachusetts Medical School. These registries have been established with the goal of systematically collecting, organizing and disseminating cell-line-specific information [23]. Their mission highlights the significance of international cooperation in the field.

\section{Informed consent}

While certain issues arise in the fields of stem cell banking and of traditional biobanking (collection of biological specimens such as DNA, tissues, bone marrow, and so on), the fields themselves have developed in parallel, seemingly without much policy cross-fertilization. For a decade, stem cell banking has long been dominated by the 'status' of the embryo issue, and tissue banking by the issue of the validity of the broad consent. However, both have moved on, the former not only due to the arrival of iPS cells, but also increasing liberal attitudes towards research involving embryos, and the latter due to acceptance of broad consent because of heightened security and governance mechanisms ensuring respect for the altruistic citizen donors involved in large population studies.

However, for both contemporary and emerging sources of stem cells, and their prospective or retrospective use, the need to resolve important issues has intensified. The ethical and policy landscape remains to be charted [29] even when dealing with core ethical principles [30], such as autonomy (informed consent, right to withdrawal), respect for privacy and confidentiality (for example, protection of donor identity given the potential for traceability of stem cell lines), and the non-commercialization of human reproductive materials (translated in restrictions on monetary compensation for gamete and tissue donation).

While informed consent requirements for stem cell derivation, use and banking have evolved along with the pace of scientific developments, significant policy variations across jurisdictions still exist for both somatic and embryonic sources [31]. Moreover, most consent requirements across jurisdictions and policy approaches still do not include consent for international exchange and research use [32].

Earlier consent requirements for the derivation of embryonic stem cell lines were often either too general or too specific [33], or did not foresee some research uses [34]. The current policy trend is to seek an informed 
consent for stem cell research, in some cases requiring consent for stem cell research from both gamete donors, and it increasingly includes the option to consent for future unspecified research uses [35]. Although consent policies are evolving, the underlying rationale for respecting such a broad consent (that is, respect for autonomy) has not been elucidated. This may be the only plausible explanation for recent decisions by funding organizations in some jurisdictions [36].

In contrast, populational resources are longitudinal and open, adding socio-demographic and environmental data over time via re-contact with participants. Created for future unspecified research, these resources, as already mentioned, balance the broad consent obtained by offering increased security and governance [9]. Retrospective research using already collected tissue and data obtains an ethics waiver, thereby avoiding the requirement of re-consent, or it re-contacts and re-consents participants where feasible, or, finally, it anonymizes the data and samples, thereby limiting their usefulness to meta-analyses or as controls [37]. Clinical residual samples are increasingly used for research under a notification system for incoming patients with a possible opt-out [38]. Traditional disease-specific research usually limits consent to the disease in question or to 'related' conditions. Absent anonymization, in all types of biobanking, traceability is possible and international research and exchange is foreseen in the consent process. The international exchange of samples is predicated on obtaining patient information. Hence, traceability is essential for the above to occur. Complete anonymization impedes the utility of such samples as it is impossible to trace the sample back to the donor.

\section{Traceability and identifiability}

Across this typology of tissue banking, and in conformity with the consent or ethics waiver, researchers agree to respect privacy and not to attempt to re-identify the donors. This obligation forms part of the informed consent process, and is also part of the material transfer agreement for access by researchers to biobanks. Together with the increasing trend to require biological resources to publish short summaries of the protocols of researchers accessing such public resources, transparency is ensured. This also underscores the commitment to donors to respect their consent and provides public feedback and monitoring. In short, identifiability and traceability are not a serious threat to privacy, but rather an assurance of safety and accountability.

Indeed, traceability of samples constitutes one of the cornerstones of stem cell banking. Traceability has been defined as 'tracking an individual through their medical history' [39]. It promotes safety and quality, but also provides a system for the tracking of handling and storage conditions and of ethical provenance. In this sense, 'biological' traceability is the equivalent of the personal data: tracing that identifiability provides via the coding of samples and data. Despite the fact that traceability is an essential component of the quality management system of stem cell banks [39], the regulations adopted in some jurisdictions make traceability unfeasible. For instance, under Canadian policy [40], the requirement to anonymize all cell lines (except autologous cells) prevents tracing back from cell to donor and limits the utility of such cell lines.

Identifiability can be defined as information that may reasonably be expected to identify an individual, alone or in combination with other available information' [41]. Even while employing coding, encryption, firewalls and other security mechanisms, it serves to respect privacy while ensuring that the accompanying clinical phenotypic data can be updated and validated. Also, with coding and thus potential identifiability, should the donors of data and samples wish to withdraw their samples or data, this fundamental right can be respected. In this it stands in contrast to anonymization, which, while ethically and legally expedient by avoiding the possibility of re-identifiability or traceability, ultimately limits eventual safety and scientific usefulness. Traceability serves to ensure quality validation while, for biobanks, identifiability allows for the ongoing updating of clinical data, making the samples more interesting for research. Withdrawal of donors of stem cells or of research participants is also possible. In the field of biobanking, novel methods and associated tools permitting individual identification in publicly accessible SNP databases have become a debatable issue $[42,43]$. There is concern that established safeguards to protect the identities of donors could be insufficient [44].

The move towards open access, to at least aggregate data and to deposit data into public domain databases (for example, PubMed) as well as into controlled access databases, is becoming both ethically sanctioned and a condition of funding of biobanks. Thus, while recently, as mentioned above, fears of re-identifiability led to an increase in controlled access databases as opposed to open access, this may change as mechanisms and algorithms are appearing that ostensibly not only serve to respond to the difficulty of transferring and sharing the sheer amount of data available, but also to shield against re-identifiability by permitting local preparation of phenotypic data prior to transfer [45]. We maintain that identifiability and traceability serve to strengthen the scientific validity and utility of research involving human tissues and can do the same for stem cell banking.

However, it should be mentioned that, in the context of embryonic stem cell research, the possibility of donor identification based solely on the hESC is extremely 
remote. The genotype of a hESC line does not correspond directly to the genotype of the individuals who donated the embryo (International Stem Cell Forum Ethics Working Party, unpublished work). Consequently, and following a proportional approach to privacy (International Stem Cell Forum Ethics Working Party, unpublished work) [46], the publication of all genotypic information for these lines in banks and registries does not seem to pose a threat to the privacy and confidentiality of donors. For other sources of stem cell lines (for example, iPs cells) and, given the considerations mentioned above, the potential for donor identifiability also seems remote.

\section{Return of results}

Lessons learned on the issue of return of results in the biobanking domain may be particularly instructive for stem cell biobanking. However, the biobanking field is awash with contradictions and confusion [47]. This may be due, in part, to the need for clarification in the terminology used. Feedback usually refers to either immediate personal communication upon enrolment of research participants or to the availability of aggregate general results via websites or newsletters upon the completion of research. In between these particular points in time, distinctions should be drawn between research results and incidental findings since context matters [48].

If enrolment in a biobank is through a medical-care setting, there may be findings of immediate significance for the care and welfare of the patient. Due to their relationship with a physician, patients in clinical trials are usually informed of validated findings of clinical utility. This stands in contrast to retrospective biobanks where re-contact to ascertain the wishes to receive results (of alive or deceased individuals) is rare. In longitudinal populational studies where participants provide data and samples for future unspecified research, the no-return approach is generally favored, as these studies serve to create infrastructures for research not to do research. But it remains to be seen whether this no-return approach will endure once secondary researchers begin to use the biobanks for disease-specific studies. Indeed, the advent of whole genome sequencing ensures that pertinent findings of clinical significance will emerge. Who will communicate these findings if at all: the biobank itself or the researcher using it?

In the specific context of stem cell research and banking, the scientific, ethical and policy implications of mandating return of results have seldom been addressed. When they have been, the possibility of returning individual or general research results is part of the informed consent process. Most policies tend to call for stem cell banks to adopt protocols governing the disclosure and management of such information back to donors. Examples of the latter are those adopted in the USA (the National Academies of Science) [49], Canada (the Interangency Advisory Panel on Research Ethics) [41], Spain (the National Stem Cell Bank) [50], and the UK (the UK Stem Cell Bank) [39]. Overall, the general trend is to inform donors that no individual return of results will be provided. One could argue that this is the best approach, as conflations of fundamental research with clinical trials wherein there are usually direct health implications could create a therapeutic misconception, leading research participants to mistakenly think that there may be personal benefit after all.

\section{Conclusions}

While this overview has attempted to trace the routes taken and the lessons learned for stem cell banking by comparison with biobanking generally, challenges remain for both. The first is perhaps best illustrated by the last topic: the return of results and its Tower of Babel confusion concerning terminology. Like the confusion surrounding 'de-identification' and anonymization before it [51], which was resolved via the International Conference on Harmonisation rules [52], this area is ripe for clarification via a common lexicon for stem cell bankers [53].

Similarly, and this applies for all forms and fields of banking, access for research needs to be streamlined and simplified. Banking is there to serve research and thereby respect the wishes of donors. Multiple and contradictory ethics reviews, often repeated again for multicenter or international studies, undermine the possibility of creating transparent and accountable governance mechanisms. Can there be a trusted third-party central clearance body or, at a minimum, a safe harbor or substantially equivalent recognition [54] between countries?

In 2008, the ISCR at the University of Massachusetts Medical School was established, with the goal of providing provenance information (scientific, ethical) on all existing pluripotent (for example, embryonic and induced pluripotent) cell lines generated worldwide. The ISCR is a searchable and comprehensive database of published and validated unpublished information on hESCs and other pluripotent stem cell lines. Since its inception, the ISCR has already compiled validated data from over 500 pluripotent cell lines [23]. Similarly, the ISSCR is establishing a Registry of Human Embryonic Stem Cell Lines Provenance [55], which is an online database providing independent validation of the ethical provenance of hESC lines. Will any of these entities become such a central clearance body? Are these two examples indicative of the emergence of a more rational and co-ordinated approach?

A model to be considered may be that of the International Cancer Genome Consortium, where countries 
who are members of the consortium agree to a set of ethical principles, procedures and general policies. Material transfer agreements are uniform, and researchers seeking access must provide proof of local ethics review and institutional responsibility for the information provided. A privacy officer (subject to oversight) approves centralized access to a federated international database [26].

Finally, another thorny issue, kept under the radar until recently, is that of diversity. To truly serve local, national and international communities, banks need to be able to find missing subpopulations and ethnic groups elsewhere so as to be representative of the modern societal mosaic as research moves to therapies [56,57]; hence the need for international exchange and access so as to accurately complete the portrait and truly serve the citizens who participate. Traceability and identifiability issues pale before the enormity of this last challenge, but the public dividends of investing in banking cannot otherwise be realized.

\section{Abbreviations}

hESC, human embryonic stem cell; iPs, induced pluripotent stem; ISCBI, International Stem Cell Banking Initiative; ISCR, International Stem Cell Registry; ISSCR, International Society for Stem Cell Research.

\section{Competing interests}

The authors declare that they have no competing interests.

\section{Authors' contributions}

Both authors contributed equally to the preparation of this manuscript. The funding sources have played no role in the design, interpretation and writing of the present study. The opinions are those of the authors alone.

\section{Acknowledgements}

We thank the Canadian Stem Cell Network (SCN) and the Canadian Institutes of Health Research (CIHR) for their funding support.

Published: 5 October 2010

\section{References}

1. Hipp J, Atala A: Sources of stem cells for regenerative medicine. Stem Cell $\operatorname{Rev} 2008,4: 3-11$

2. Day JG, Stacey GN: Biobanking. Mol Biotechno/ 2008, 40:202-213.

3. Organisation for Economic Co-operation and Development: The Bioeconomy to 2030: Designing A Policy Agenda 2009 [http://www.oecd. org/document/48/0,3343,en_2649_36831301_42864368_1_1_1_1,00.html]

4. Sermon KD, Simon C, Braude P, Viville S, Borstlap J, Veiga A: Creation of a registry for human embryonic stem cells carrying an inherited defect: joint collaboration between ESHRE and hESCreg. Hum Reprod 2009, 24:1556-1560.

5. Reproductive Genetics Institute Stem Cell Bank [http://reproductivegenetics. com/stem_cell_bank.html]

6. WiCell Research Institute WISC Bank [http://www.wicell.org/index php?option=com_oscommerce\&ltemid=192\#iPS]

7. Isasi RM, Knoppers BM: Beyond the permissibility of embryonic and stem cell research: substantive requirements and procedural safeguards. Hum Reprod 2006, 21:2474-2481

8. Isasi R, Knoppers BM: Governing stem cell banks and registries: emerging issues. Stem Cell Res 2009, 3:96-105.

9. Cambon-Thomsen A, Rial-Sebbag E, Knoppers BM: Trends in ethical and legal frameworks for the use of human biobanks. Eur Respir J 2007, 30:373-382.

10. Stacey GN: Sourcing human embryonic stem cell lines. In Human Embryonic Stem Cells: The Practical Handbook. Edited by Sullivan S, Cowan CA, Eggan K. New Jersey: John Wiley and Sons; 2007:11-24.
11. Organisation for Economic Co-operation and Development: Guidelines for Human Biobanks and Genetic Research Databases (HBGRDs) 2009 [http://www.oecd.org/document/12/ 0,3343,en_2649_34537_40302092_1_1_1_1,00.html]

12. Burton PR, Hansell AL, Fortier I, Manolio TA, Khoury MJ, Little J, Elliott P: Size matters: just how big is BIG? Quantifying realistic sample size requirements for human genome epidemiology. Int J Epidemiol 2009, 38:263-273.

13. Park A: Ten ideas changing the world right now: biobanks. Time 12 March 2009 [http://www.time.com/time/specials/packages/ article/0,28804,1884779 1884782_1884766,00.html]

14. Caulfield T, Scott C, Hyun I, Lovell-Badge R, Kato K, Zarzeczny A: Stem cell research policy and iPS cells. Nat Methods 2010, 7:28-33.

15. Lo B, Conklin BR: Consent: criteria should be drawn up for tissue donors. Nature 2009, 461:593.

16. Lipworth W, Irvine R, Morrell B: Consent: a need for guidelines to reflect local considerations. Nature 2009,461:593.

17. Aalto-Setälä K, Conklin BR, Lo B: Obtaining consent for future research with induced pluripotent cells: opportunities and challenges. PLOS Biol 2009, 7:e42.

18. Lowrance WW, Collins FS: Ethics. Identifiability in genomic research. Science 2007, 317:600-602

19. Lo B, Parham L, Alvarez-Buylla A, Cedars M, Conklin B, Fisher S, Gates E, Giudice L, Halme DG, Hershon W, Kriegstein A, Kwok PY, Wagner R: Cloning mice and men: prohibiting the use of iPS cells for human reproductive cloning. Cell Stem Cell 2010, 6:16-20.

20. Knoppers BM, Fortier I, Legault D, Burton P: The Public Population Project in Genomics (P3G): a proof of concept? Eur J Hum Genet 2008, 16:664-665.

21. Organisation for Economic Co-operation and Development: OECD Best Practice Guidelines for Biological Resource Centres, 2007 [http://www. oecd.org/dataoecd/7/13/38777417.pdf]

22. Baust JG: ISBER best practices for repositories and trends at the Institute for Problems of Cryobiology and Medicine. Cell Preserv Techno/ 2008, 6:1.

23. Borstlap J, Luong MX, Rooke HM, Aran B, Damaschun A, Elstner A, Smith KP, Stein GS, Veiga A: International stem cell registries. In Vitro Cell Dev Biol Anim 2010, 46:242-246.

24. Zika E, Paci D, Schulte T, Braun A, Rijkers-Defrasne S, Deschênes M, Fortier I, Laage-Hellman J, Scerri CA, Ibarreta I: Biobanks in Europe: prospects for harmonisation and networking. Seville: European Joint Research Commission and Institute for Prospective Technological Studies; 2010 [http:// ftp.jrc.es/EURdoc/JRC57831.pdf

25. Fortier I, Burton PR, Robson PJ, Ferretti V, Little J, L'heureux F, Deschênes M, Knoppers BM, Doiron D, Keers JC, Linksted P, Harris JR, Lachance G, Boileau C, Pedersen NL, Hamilton CM, Hveem K, Borugian MJ, Gallagher RP, McLaughlin J, Parker L, Potter JD, Gallacher J, Kaaks R, Liu B, Sprosen T, Vilain A, Atkinson SA, Rengifo A, Morton R: Quality, quantity and harmony: the DataSHaPER approach to integrating data across bioclinical studies. Int J Epidemio/ 2010, in press.

26. International Cancer Genome Consortium: Consortium Policies and Guidelines: Informed Consent, Access and Ethical Oversight [http://www. icgc.org/icgc/goals-structure-policies-guidelines/ e1-informed-consent-access-and-ethical-oversight]

27. Crook JM, Hei D, Stacey G: The International Stem Cell Banking Initiative (ISCBI): raising standards to bank on. In Vitro Cell Dev Biol Anim 2010, 46:169-172.

28. International Stem Cell Banking Initiative: Consensus guidance for banking and supply of human embryonic stem cell lines for research purposes. Stem Cell Rev 2009, 5:301-314

29. Zarzeczny A, Scott C, Hyun I, Bennett J, Chandler J, Chargé S, Heine H, Isasi R, Kato K, Lovell-Badge R, McNagny K, Pei D, Rossant J, Surani A, Taylor PL, Ogbogu U, Caulfield T: iPS cells: mapping the policy issues. Cell 2009 139:1032-1036.

30. Lo B, Parham L: Ethical issues in stem cell research. Endocr Rev 2009, 30:204-213.

31. Sugarman J, Siegel AW: Research ethics. When embryonic stem cell lines fail to meet consent standards. Science 2008, 322:379.

32. Lo B, Parham L, Broom C, Cedars M, Gates E, Giudice L, Halme DG, Hershon W, Kriegstein A, Kwok PY, Oberman M, Roberts C, Wagner R: Importing human pluripotent stem cell lines derived at another institution: tailoring review to ethical concerns. Cell Stem Cell 2009, 4:115-123.

33. Streiffer $R$ : Informed consent and federal funding for stem cell research. 
Hastings Cent Rep 2008, 38:40-47.

34. Editorial: Common consent. Nature 2009, 460:933.

35. Conrad S, Renninger M, Hennenlotter J, Wiesner T, Just L, Bonin M, Aicher W, Bühring HJ, Mattheus U, Mack A, Wagner HJ, Minger S, Matzkies M, Reppel M, Hescheler J, Sievert KD, Stenzl A, Skutella T: Generation of pluripotent stem cells from adult human testis. Nature 2008, 456:344-349. [A published erratum appears in Nature 2009, 460:1044.]

36. Wadman M: Diseased cells fail to win approval. Nature 2010, 465:852.

37. Tassé AM, Budin-Ljøsne I, Knoppers BM, Harris JR: Retrospective access to data: the ENGAGE consent experience. Eur J Hum Genet 2010, 18:741-745.

38. Pulley J, Clayton E, Bernard GR, Roden DM, Masys DR: Principles of human subjects protections applied in an opt-out, de-identified biobank. Clin Trans/ Sci 2010, 3:42-48

39. Medical Research Council: Code of Practice for the use of Human Stem Cell Lines, April 2010 [http://www.mrc.ac.uk/Utilities/Documentrecord/index. htm?d=MRC003132]

40. Canadian Institutes for Health Research (CIHR): Human Pluripotent Stem Cell Research: Recommendations for ClHR-Funded Research, 2002 (updates published in 2006, 2007 and 2010) [http://www.cihr-irsc.gc.ca/e/1489.html]

41. Interagency Secretariat on Research Ethics: Provisional final draft of the tri-council policy statement: ethical conduct for research involving humans (TCPS), 12 May 2010 [http://www.pre.ethics.gc.ca/eng/policypolitique/initiatives/draft-preliminaire/]

42. Homer N, Szelinger S, Redman M, Duggan D, Tembe W, Muehling J, Pearson $J$, Stephan DA, Nelson SF, Craig DW: Resolving individuals contributing trace amounts of DNA to highlight complex mixtures using high-density SNP genotyping microarrays. PLoS Genet 2008, 4:e1000167.

43. Lin Z, Altman RB, Owen AB: Genomic research and human subject privacy. Science 2004, 305:183.

44. $P^{3} G$ consortium, Church G, Heeney C, Hawkins N, de Vries J, Boddington P, Kaye J, Bobrow M, Weir B: Public access to genome-wide data: five views on balancing research with privacy protection. PLoS Genet 2009, 5:e1000665.

45. Wolfson M, Wallace SE, Masca N, Rowe G, Sheehan NA, Ferretti V, Laflamme P, Tobin MD, Macleod J, Little J, Fortier I, Knoppers BM, Burton PR: DataSHIELD: resolving a conflict in contemporary bioscience - performing a pooled analysis of individual-level data without sharing the data. Int J Epidemiol 2010, in press.

46. Data Protection Working Party: Opinion 4/2007 on the Concept of Personal Data [www.gov.gg/ccm/cms-service/download/asset/?asset_id=12058063]
47. Miller FA, Hayeems RZ, Bytautas JP: What is a meaningful result? Disclosing the results of genomic research in autism to research participants. Eur $J$ Hum Genet 2010, 18:867-871.

48. Beskow LM, Burke W: Offering individual genetic research results: context matters. Sci Trans/ Med 2010, 2:38cm20.

49. National Research Council and Institute of Medicine: 2010 Amendments to the National Academies' Guidelines for Human Embryonic Stem Cell Research. Washington, DC: The National Academies Press; 2010.

50. Instituto de Salud Carlos III, Comité de Ética en la Investigación y de Bienestar Animal: Hoja de Información a los Participantes en la Investigación (Document CEI HIPCI IPS). Madrid: Instituto de Salud Carlos III; 2010.

51. Knoppers BM, Saginur M: The Babel of genetic data terminology. Nat Biotechnol 2005, 23:925-927.

52. U.S. Department of Health and Human Services Food and Drug Administration: Guidance for Industry. E15 Definitions for Genomic Biomarkers, Pharmacogenomics, Pharamacogenetics, Genomic Data and Sample Coding Categories. [http://www.fda.gov/downloads/Drugs/ GuidanceComplianceRegulatoryInformation/Guidances/ucm073162.pdf]

53. American Type Culture Collection Standards Development Organization Workgroup: Cell line misidentification: the beginning of the end. Nat Rev Cancer 2010, 10:441-448.

54. Isasi R: Policy interoperability in stem cell research: demystifying harmonization. Stem Cell Rev 2009, 5:108-115.

55. International Society for Stem Cell Research (ISSCR): Guidelines for the Conduct of Human Embryonic Stem Cell Research. [http://www.isscr.org/ guidelines/ISSCRhESCguidelines2006.pdf]

56. Mosher JT, Pemberton TJ, Harter K, Wang C, Buzbas EO, Dvorak P, Simón C Morrison SJ, Rosenberg NA: Lack of population diversity in commonly used human embryonic stem-cell lines. N Engl J Med 2010, 362:183-185.

57. Laurent LC, Nievergelt CM, Lynch C, Fakunle E, Harness JV, Schmidt U, Galat V, Laslett AL, Otonkoski T, Keirstead HS, Schork A, Park HS, Loring JF: Restricted ethnic diversity in human embryonic stem cell lines. Nat Methods 2010, $7: 6-7$

doi:10.1186/gm194

Cite this article as: Knoppers BM, Isasi R: Stem cell banking: between traceability and identifiability. Genome Medicine 2010, 2:73. 